\title{
PENGARUH KEPEMIMPINAN TRANSFORMASIONAL DAN EFIKASI DIRI TERHADAP KEPUASAAN KERJA GURU
}

\section{THE EFFECT OF TRANSFORMATIONAL LEADERSHIP AND SELF EFFICACY OF THE JOB SATISFACTION TEACHER}

\author{
N Karnati1a dan A Wiratma ${ }^{2}$ \\ ${ }^{1}$ Program Studi Manajemen Pendidikan, Pascasarjana, Universitas Negeri Jakarta, \\ Jl. Rawamangun Muka, Jakarta Timur, Daerah Khusus Ibukota Jakarta \\ 2 Produser dan Presenter Berita Globaltv (MNC Group) dan Relawan Pendidikan di Akademi \\ Indonesia Sekolah Darurat Kartini \\ a Korespondensi: Neti Karnati, Email: netiyupan@yahoo.com \\ (Diterima: 14-06-2017; Ditelaah: 15-06-2017; Disetujui: 29-08-2017)
}

\begin{abstract}
The purpose of this study is to determine the effect of transformational leadership and self efficacy of the job satisfaction teacher in Junior High School of Budi Mulia Lourdes Jakarta.The research methodology was survey which was selected by simple random sampling technique. Analysis and interpretation of the data indicates that (1) transformational leadership of a positive direct effect on job satisfaction, (2) self efficacy positive direct effect on job satisfaction, (3) transformational leadership positive direct effect on the self efficacy.
\end{abstract}

Keywords: transformational leadership, self efficacy, job satisfaction.

\begin{abstract}
ABSTRAK
Tujuan dari penelitian ini adalah untuk mengetahui pengaruh kepemimpinan transformasional dan efikasi diri terhadap kepuasan kerja guru di SMP Yayasan Budi Mulia Lourdes Jakarta. Metodologi penelitian adalah survei yang dipilih dengan teknik simple random sampling. Analisis dan interpretasi data menunjukkan bahwa (1) kepemimpinan transformasional berpengaruh positif langsung terhadap kepuasan kerja, (2) efikasi diri berpengaruh langsung positif terhadap kepuasan kerja, (3) kepemimpinan transformasional berpengaruh positif langsung terhadap efikasi diri.
\end{abstract}

Kata kunci: efikasi diri, kepemimpinan transformasional, kepuasan kerja.

Karnati N dan A Wiratma. 2017. Pengaruh kepemimpinan transformasional dan efikasi diri terhadap kepuasan kerja guru. Jurnal Sosial Humaniora 8(2): 85 - 92.

\section{PENDAHULUAN}

Pendidikan adalah tema yang tidak pernah basi, senantiasa menarik dan relevan untuk dibicarakan di mana pun dan kapan pun, bahkan di negara maju sekalipun. Begitu juga di Indonesia, setiap masa pemerintahan, pendidikan selalu ramai didiskusikan, karena memang masih banyak masalah yang menyelimutinya. Tidak hanya soal pendidikan di daerah terpencil, pedalaman atau wilayah terluar, masalah pendidikan juga terjadi di kota-kota besar seperti Jakarta.

Dalam Undang-Undang No. 20 tahun 2003 tentang Sistem Pendidikan Nasional dikatakan pendidikan adalah "pendidikan adalah usaha sadar dan terencana untuk mewujudkan suasana belajar dan proses pembelajaran agar peserta didik secara aktif 
mengembangkan potensi dirinya untuk memiliki kekuatan spiritual keagamaan, pengendalian diri, kepribadian, kecerdasan, akhlak mulia, serta keterampilan yang diperlukan dirinya, masyarakat, bangsa dan negara." Definisi pendidikan tersebut jika dicermati tidak hanya sekedar menggambarkan tentang apa pendidikan, tetapi memiliki makna dan implikasi yang luas tentang siapa sesunguhnya pendidik itu, siapa peserta didik (siswa) itu, bagaimana seharusnya mendidik, dan apa yang ingin dicapai oleh pendidikan.

Pendidikan adalah kunci dan merupakan aset penting bagi kemajuan pembangunan sebuah bangsa. Dengan pendidikan, cita-cita bangsa yang sejahtera, adil dan makmur sesuai dengan amanat konstitusi dapat tercapai. Namun harus diakui kualitas pendidikan di Indonesia hingga saat ini masih memprihatinkan. Ini dapat dibuktikan dengan Indeks Pembangunan Manusia (IPM) Indonesia yang masih rendah. Indonesia berada di posisi ke-108 pada tahun 2013 dalam Laporan Pembangunan Manusia atau Human Development Report (HDR) yang dikeluarkan Lembaga PBB untuk Pembangunan atau United Nations Development Programme (UNDP). Di mata dunia, mutu pendidikan Indonesia juga masih rendah dibandingkan dengan negaranegara lain. The Learning Curve Pearson 2014, lembaga pemeringkatan pendidikan dunia memaparkan jika Indonesia menduduki posisi akhir dalam mutu pendidikan, Indonesia menempati posisi ke40.

Banyak faktor saat kita menyebut kualitas pendidikan Indonesia rendah, diantaranya guru. Kualitas kerja guru terlihat dari produk yang dihasilkan dalam bekerja. Hasil belajar dapat tercapai secara optimal jika ada kegairahan dan semangat guru untuk bekerja. Guru yang memiliki kepuasan kerja yang tinggi, akan bekerja sesuai koridor yang ada. Profesionalitasnya muncul sebagai konsekuensi dari keinginan untuk bekerja secara maksimal dalam menyelesaikan setiap pekerjaan.
Peristiwa yang menunjukan ketidakpuasan guru sempat menjadi bahan pemberitaan media nasional, diantaranya aksi ribuan guru honorer di depan Istana Negara pada bulan Mei 2014. Mereka menuntut agar segera diangkat menjadi Pegawai Negeri Sipil tanpa dilakukan tes. Pasalnya banyak guru honorer yang telah mengabdi hingga 20 tahun namun belum mendapatkan kesejahteraan. Sebelumnya pada 15 Januari 2014, Aktivitas kegiatan belajar mengajar di SMKN 1 Bua, Palopo, Sulawesi Selatan, lumpuh total setelah ratusan siswanya bersama unsur guru melakukan aksi unjuk rasa. Aksi itu dilakukan menyusul sikap Kepala Sekolah dan Wakilnya yang dinilai sering membolos. Aksi yang sama juga dilakukan guru Madrasah Aliyah Negeri (MAN) 1 Kota Bogor, mereka protes dipindahkannya guru Matematika ke sekolah madrasyah lainnya tanpa alasan jelas (5 Maret 2014).

Berbagai permasalahan yang muncul tersebut menunjukkan bahwa kepuasan kerja guru belum tercapai. Bicara kepuasan kerja, hal itu tidak hanya diukur dari besaran gaji atau upah yang diberikan. Terdapat faktor lainnya, yakni kepemimpinan kepala sekolah, serta penilaian individu guru terhadap keyakinan diri akan kemampuannya dalam menjalankan tugas atau disebut dengan efikasi diri.

\section{MATERI DAN METODE}

\section{Materi}

\section{Kepuasan Kerja}

Seorang guru dalam bekerja akan memiliki semangat dan kesetiaan yang tinggi pada tugasnya apabila guru tersebut memperoleh kepuasan kerja sesuai dengan yang diinginkannya. Ada pernyataan yang mengatakan bahwa kepuasan itu perasaan menyenangkan, merupakan hasil dari persepsi individu dalam rangka menyelesaikan tugas atau memenuhi kebutuhannya untuk memperoleh nilai-nilai kerja yang penting bagi dirinya Istilah 
kepuasan kerja merupakan terjemahan dari bahasa Inggris "job satisfaction".

Steven M. Jax (2002:116) menyatakan, "job satisfaction is typically defined as an employees level of positive affect toward his or her job situation". Sementara menurut Gibson, Invancevich \& Donelly (1997:106), "job satisfaction is an attitude that individuals have about their jobs. It results from their perceptions of their jobs, based on factors of the work environment, such as the supervisor's style, policies, and procedures, work group affiliation, working conditions and fringe benefits." Berarti kepuasaan kerja adalah sikap seseorang terhadap pekerjaan mereka. Hal tersebut dihasilkan dari persepsi mereka mengenai pekerjaan dan tingkat kesesuaian antara individu dan organisasi. Hal itu juga disampaikan Schermerhorn (2005:385), "job satisfactionis is the degree to which an individual feels positive or negative about a job".

Terkait kepuasan kerja juga disampaikan Robbins (1997:31) yang menyatakan, "job satisfactions refer to an individual's general attitude toward his or her job. A person with a high level of job satisfaction holds positive attitudes toward the job, and a person who is dissatisfied with his or her job holds negative attitude about that job". Kepuasan kerja mengacu pada sikap umum seorang individu terhadap pekerjaannya. Seseorang dengan tingkat tinggi kepuasan kerja memegang sikap positif terhadap pekerjaan, dan orang yang tidak puas dalam pekerjaannya memegang sikap negatif tentang pekerjaan itu.

Kemudian Kreitner \& Kinicki (1992:58), menyatakan bahwa, "job satisfaction is an affective or emotional respond toward various". Bahwa kepuasan kerja merupakan afektif atau respon emosional terhadap berbagai aspek pekerjaan seseorang. Ada tiga hal yang diungkapkan tentang kepuasan kerja, yakni perasaan, respon emosional dan kondisi pekerjaan.

Seperti yang disampaikan Laurie J. Mullins (2005:700), "job satisfaction is an emotion a feeling, an attitude and matter of perception. It result from an appraisal of an employee's experiences at work. Job satisfaction involves likes, dislike, extrinsic and intrinsic". Kepuasan kerja adalah emosi perasaan, sikap dan masalah persepsi. Hal itu adalah hasil penilaian dari pengalaman karyawan di tempat kerja. Kepuasan kerja melibatkan perasaan suka, tidak suka, ekstrinsik, dan intrinsik.

Berdasarkan definisi di atas dapat disintesiskan bahwa kepuasan kerja adalah keadaan emosional yang disebabkan oleh penilaian pekerja atau pengalaman kerja dengan indikator: perasaan terhadap imbalan, perasaan terhadap tanggung jawab, perasaan terhadap peluang promosi, perasaan terhadap rekan kerja, perasaan terhadap kondisi pekerjaan, perasaan terhadap kepercayaan, perasaan terhadap sikap kerja.

\section{Kepemimpinan Transformasional}

Kepemimpinan transformasional dapat didefinisikan sebagai gaya kepemimpinan yang mengutamakan pemberian kesempatan, dan atau mendorong semua unsur yang ada dalam sekolah untuk bekerja atas dasar sistem nilai (values system) yang luhur, sehingga semua unsur yang ada di sekolah (guru, siswa, pegawai, orangtua siswa, masyarakat, dan sebagainya) bersedia, tanpa paksaan, berpartisipasi secara optimal dalam mencapai tujuan ideal sekolah.

Kata transformasional berasal dari kata to transform yang bermakna mentransformasikan atau mengubah sesuatu menjadi bentuk lain yang lain yang berbeda. Misalnya, mentransformasikan visi menjadi realita, potensi menjadi energi nyata, motif berprestasi menjadi prestasi nyata. Istilah dan konsep kepemimpinan transformasional

(transformational leadership) dimulai oleh James McGregor Burns. Dikutip dari buku Leadership in Organizations, Gery Yulk (1989:210) menyebut bahwa Burns menggunakan istilah mentransformasi kepemimpinan (transforming leadership), dimana yang ditransformasikan adalah 
kepemimpinannya dari pemimpin ke pengikut.

Masih menurut Burns yang dikutip Owen, Hodgoson dan Gazzard (2004:312), "transforming leadership ultimately becomes moral in that it raises the level of human conduct and ethical aspirations of both the leader and led, and thus has a transforming effect on both. He called this transformational leadership." Mentransformasikan kepemimpinan akhirnya menjadi moral dengan begitu menaikkan tingkat tingkah laku manusia dan aspirasi etika keduanya, pemimpin dan memimpin. Dia menyebutnya dengan kepemimpinan transformasional.

Kepemimpinan transformasional berbeda dengan kepemimpinan transaksional pada empat wilayah yang signifikan, yaitu (1) Kepemimpinan mengembangkan pemimpin, transformasional transformasional mengangkat kepedulian pengikut dari tingkat terendah, kebutuhan fisik (seperti keselamatan dan keamanan) ke tingkat yang lebih tinggi, kebutuhan psikologi (seperti kekaguman diri dan aktualisasi diri), (3) Kepemimpinan transformasional menginspirasi pengikutnya untuk memajukan kepentingan mereka sendiri untuk kepentingan kelompok, (4) Kepemimpinan transformasional melukiskan visi dari keinginan keadaan masa depan dan mengkomunikasikannya dengan membuat sulit nilai perubahan usaha.

Kemudian Leithwood dalam buku Sudarwan Danim (2007:219) menyatakan, "transformational leadership is seen to be sensitive to organization building, developing shared vision, distributing leadership and building school culture necessary to current restructuring efforts in school." Sementara Soon Lim dan Richard L. Daft (2004:152) memberikan pengertian, "transformational leadership is based on the personal values, beliefs, and qualities of the leader rather than on an exchange process between leaders and followers". Kepemimpinan transformasional berdasarkan nilai-nilai individu, kepercayaan, dan kualitas pemimpin, lebih dari proses pertukaran antara pemimpin dan pengikut. Selanjutnya Daft (1999:427) mengatakan Kepemimpinan transformasional dikarakteristikkan dengan kemampuan membawa perubahan yang signifikan. Pemimpin transformasional memiliki kemampuan untuk memulai perubahan pada visi organisasi, strategi dan budaya sebaik mempromosikan inovasi produk dan teknologi.

Kepemimpinan transformasional sebagai pengaruh pemimpin atau atasan terhadap bawahan. Para bawahan merasakan adanya kepercayaan, kebanggaan, loyalitas dan rasa hormat kepada atasan, dan mereka termotivasi untuk melakukan melebihi apa yang diharapkan. Kepemimpinan transformasional harus dapat mengartikan dengan jelas mengenai visi untuk organisasi, sehingga pengikutnya akan menerima kredibilitas pemimpin tersebut. Dengan bahasa sederhana, kepemimpinan transformasional dapat didefinisikan dan dipahami sebagai kepemimpinan yang mampu mendatangkan perubahan di dalam diri setiap individu yang terlibat atau bagi seluruh organisasi untuk mencapai performa yang semakin tinggi.

Dari uraian-uraian di atas dapat disintesiskan kepemimpinan transformasional adalah proses mempengaruhi seorang pemimpin dalam bekerja dengan dan/atau melalui orang lain untuk mentransformasikan secara optimal sumber daya organisasi (fasilitas, dana, faktor-faktor eksternal organisasi, sumber daya manusia) dalam rangka mencapai tujuan yang bermakna sesuai dengan target capaian yang telah ditetapkan. Dengan indikator komunikasi efektif, memberikan arahan, memberikan bantuan, memberikan penugasan dan mengambil keputusan.

\section{Efikasi Diri}

Efikasi diri (Self efficacy) merupakan salah satu aspek pengetahuan tentang diri atau self knowledge yang memiliki pengaruh dalam kehidupan manusia sehari-hari dalam bekerja. Hal ini disebabkan self efficacy yang 
dimiliki ikut mempengaruhi individu dalam menentukan tindakan yang akan dilakukan untuk mencapai suatu tujuan.

Ghee Soon Lim dan Richard L. Daft (1999:306) mengemukakan, "self efficacy is the capacity to produce result or outcomes, to feel that they are effective". Efikasi diri adalah kecakapan untuk memperoleh hasil atau keluaran, mampu mengetahui tindakan yang efektif. Self efficacy berhubungan dengan keyakinan pribadi mengenai kompetensi dan kemampuan diri. Kompetensi menggambarkan keyakinan seseorang pada kemampuan/kapasitasnya untuk menyelesaikan tugas-tugas kerja dengan baik. Kompetensi sering didefinisikan sebagai konsep self efficacy; karyawankaryawan dengan kompetensi (self efficacy) yang kuat memiliki keyakinan bahwa mereka mampu mengemban tugas-tugas khusus yang diperlukan untuk meraih kesuksesan pada pekerjaan.

Ricky W.Griffin dan Gregory Moorhead (2014:69) mendefinisikan self efficacy sebagai, "a person's self efficacy is that person's beliefs about his or her capabilities to perform a task". Keyakinan seseorang terhadap kemampuannya untuk menyelesaikan sebuah tugas kerja. Sementara Robert Kreitner dan Angelo Kinicki (2010:128) mengemukakan, "self efficacy is a person's belief about his or her chances of successfully accomplishing a specific task". Keyakinan diri seseorang pada keberhasilannya untuk menyelesaikan tugas tertentu.

Selanjutnya Walter C.Borman, Daniel R. Ugen dan Richard J. Klimoski (2010:128) mendefinisikan self efficacy sebagai berikut, "self efficacy is an individual's belief that she or he competent, the issue of subjective competence can be discussed within thee self efficacy framework". Efikasi diri adalah keyakinan seseorang pada kemampuan yang dimilikinya, masalah utama dari kompetensi dapat dibahas dalam kerangka self efficacy.

Kemudian Mcshane dan Von Glinow 2010:45) mendefinisikan self efficacy sebagai, "self efficacy is a person's belief that he or she has the ability, motivation, correct role perceptions, and favorable situation to complete a task successfully". Keyakinan seseorang terhadap kemampuannya, motivasi, persepsi-persepsi aturan yang benar dan kondisi yang baik untuk menyelesaikan tugas kerja dengan sukses. Hal yang sama dikemukakan Luthans (2010:203), "The formal definition of selfefficacy that is usually used is Bandura's early statement of personal judgment or belief of how well one can execute courses of action required to deal with prospective situations. Efikasi diri adalah bagaimana seseorang dengan baik dapat melakukan sesuatu dari tindakan yang diperlukan sesuai dengan situasi yang akan timbul.

Berdasarkan uraian di atas dapat disintesiskan self efficacy adalah keyakinan seseorang terhadap dirinya sendiri untuk menyelesaikan tugas dan tanggung jawab kerja yang diemban dengan baik, dengan indikatornya meliputi: (1) kegigihan dalam bekerja, (2) dapat menyelesaikan masalah yang dihadapi, (3) berusaha menyelesaikan tugas, (4) mengatasi situasi kerja.

\section{Metode}

Metode yang digunakan dalam penelitian ini adalah penelitian survei dengan pendekatan kuantitatif. Analisis data menggunakan analisis jalur (path analysis). Teknik ini dipilih dengan pertimbangan akan digunakan untuk menguji hubungan antar variabel, dan selanjutnya mengetahui pengaruh langsung antara variabel-variabel bebas (independen) terhadap variabel terikat (dependen).

Populasi target dalam penelitian ini adalah seluruh guru di SMP Yayasan Budi Mulia Lourdes Jakarta. Populasi terjangkau yang akan diteliti tersebar di empat sekolah total populasi guru sebanyak 133 orang. Penentuan sampel dilakukan secara acak, dengan menggunakan teknik simple random sampling (sampel acak sederhana) yang dilakukan dengan cara pengundian. Penentuan jumlah sampel guru yang menjadi objek penelitian ditentukan dengan rumus Slovin. Jadi jumlah sampel dalam penelitian ini, sebanyak 100 orang guru. 


\section{HASIL DAN PEMBAHASAN}

\section{Pengaruh \\ kepemimpinan transformasional terhadap kepuasan kerja}

Dari hasil perhitungan analisis jalur, terdapat pengaruh langsung positif kepemimpinan transformasional terhadap kepuasan kerja dengan nilai koefisien korelasi sebesar 0,334 dan nilai koefisien jalur sebesar 0,263. Ini memberikan makna kepemimpinan transformasional berpengaruh langsung terhadap kepuasan kerja.

Hal ini sesuai dengan yang dikemukakan Neal M. Ashkanasy, Chaimine EJ. Hartel, and Wilfred J. Zerbe, "the next aspect to be considered is the effect of transformational leadership on affective work outcomes. Research evidence has shown that an individual's view on his or her occupation and career affect job satisfaction. If individuals' view can be altered to generate a higher job satisfaction level, this could lead to effect at the organization level". Aspek berikutnya yang harus dipertimbangkan adalah efek kepemimpinan transformasional pada hasil kerja efektif. Bukti penelitian telah menunjukkan bahwa pandangan individu tentang dirinya, pekerjaan dan karir mempengaruhi kepuasan kerja. Jika pandangan individu dapat diubah untuk menghasilkan tingkat kepuasan kerja yang lebih tinggi, hal ini dapat menyebabkan efek pada tingkat organisasi. Hal ini berarti ketepatan kepemimpinan transformasional menyebabkan ketepatan dalam kepuasan kerja guru.

\section{Pengaruh efikasi diri terhadap kepuasan kerja}

Dari hasil perhitungan analisis jalur, terdapat pengaruh langsung positif efikasi diri terhadap kepuasan kerja dengan nilai koefisien korelasi sebesar 0,331 dan nilai koefisien jalur sebesar 0,259. Ini memberikan makna efikasi diri berpengaruh langsung terhadap kepuasan kerja.

Hal tersebut sama dengan pendapat Carol Lee Mc Arthur, yang menyatakan, "self efficacy beliefs have been found to be the "main determinants" of teachers job satisfaction. Further, perception of collective efficacy are influential in the development of teacher job satisfaction. Specially, these researchers determined that constructs are most significant at the school level of the organization". Keyakinan self efficacy telah ditemukan untuk menjadi "penentu utama" kepuasan kerja guru. Selanjutnya, persepsi efikasi kolektif yang berpengaruh dalam pengembangan kepuasan kerja guru. Khususnya, para peneliti menentukan bahwa konstruksi yang paling signifikan di tingkat organisasi sekolah. Hal ini berarti ketepatan kepemimpinan transformasional menyebabkan ketepatan dalam kepuasan kerja guru.

\section{Pengaruh} transformasional terhadap efikasi diri.

Dari hasil perhitungan analisis jalur terdapat pengaruh langsung positif kepemimpinan transformasional terhadap efikasi diri dengan nilai koefisien korelasi sebesar 0,273 dan nilai koefisien jalur sebesar 0,273. Ini memberikan makna kepemimpinan transformasional berpengaruh langsung terhadap efikasi diri.

Hasil penelitian ini senada dengan pendapat Kenneth Leithwood and Rosanne Stainbach, yang menyatakan bahwa, "transformational leaders increase their staffs' commitment by "recruiting" their self concept, by increasing the salience of certain identities and values to an organization vision and mission that reflects them. These transformational leadership effects can be explained as a product of conditions which enhance staff motivation and perceptions of self efficacy". Pemimpin transformasional meningkatkan komitmen staf mereka dengan "merekrut" berdasarkan pada konsep diri mereka, dengan meningkatkan arti-penting dari identitas dan nilai-nilai tertentu untuk sebuah visi dan misi organisasi yang mencerminkan mereka.Efek kepemimpinan transformasional dapat dijelaskan sebagai produk dari kondisi yang 
meningkatkan motivasi staf dan persepsi efikasi diri. Hal ini berarti ketepatan kepemimpinan tranformasinoal menyebabkan ketepatan dalam efikasi diri guru.

\section{KESIMPULAN DAN IMPLIKASI}

\section{Kesimpulan}

Berdasarkan hasil penelitian dan pembahasan yang telah dilakukan maka dapat ditarik kesimpulan umum yaitu terdapat pengaruh positif kepemimpinan transformasional dan efikasi diri terhadap kepuasan kerja guru SMP Yayasan Budi Mulia Lourdes Jakarta. Secara khusus dapat disimpulkan sebagai berikut: (1) Kepemimpinan transformasional berpengaruh langsung positif terhadap kepuasan kerja guru SMP Yayasan Budi Mulia Lourdes Jakarta. (2) Efikasi diri berpengaruh langsung positif terhadap kepuasan kerja guru SMP Yayasan Budi Mulia Lourdes Jakarta. (3) Kepemimpinan transformasional berpengaruh langsung positif terhadap efikasi diri guru SMP Yayasan Budi Mulia Lourdes Jakarta.

\section{Implikasi}

Sehubungan dengan beberapa kesimpulan dan implikasi penelitian yang telah dikemukakan dan keterbatasan jangkauan penelitian maka berikut disampaikan beberapa saran: (1) Bagi Dinas Pendidikan, hendaknya memberikan kesempatan seluasluasnya kepada guru untuk melakukan pengembangan keprofesionalan guru dengan mengadakan berbagai macam pendidikan dan pelatihan, seminar yang menarik, workshop dan kegiatan kolektif guru lainnya sehingga guru selalu dapat berkembang dan belajar serta mendapatkan pengetahuan dan keterampilan yang bermanfaat bagi pengembangan karirnya. Kegiatan tersebut diharapkanakan meningkatkan kepemimpinan dan efikasi diri yang akhirnya dapat meningkatkan kepuasan kerja guru. (2) Bagi Kepala SMP Yayasan Budi Mulia Lourdes Jakarta, hendaknya dengan kepemimpinan transformasional di sekolah mampu mempengaruhi guru dengan hal-hal yang baik, melaksanakan tugas dengan rasa percaya diri, bekerja dengan penuh semangat dan menjalin hubungan dengan berbagai pihak. (3) Khusus untuk guru SMP Yayasan Budi Mulia Lourdes Jakarta, di samping melaksanakan tugas-tugas mengajarnya hendaknya juga diharapkan dapat meningkatkan kemampuan dan kompetensinya agar dapat meningkatkan tercapainya kepuasan kerja disekolah. Pihak sekolah sebaiknya mengadakan pelatihanpelatihan atau seminar untuk memotivasi diri para guru agar memiliki keyakinan yang kuat dalam mengajar di kelas. (4) Bagi peneliti lain, dapat dijadikan bahan rujukan dalam rangka penelitian lebih lanjut terkait dengan kepemimpinan transformasional dan efikasi diri terhadap kepuasan kerja.

\section{DAFTAR PUSTAKA}

Ashkanasy, M., Chaimine EJ Hartel, and Wilfred J. Zerbe, Emotions in The Workplace, Research, Theory, and Practice, Greenwood Publishing Group, Inc, 2000.

Bass, Bernard M., Leadership and Performance Beyond Expectation, New York: The Free Press, 1985.

Borman, Walter C., Daniel R. Ugendan Richard J.Klimoski, Handbook of Psychology, New Jersey: John Wiley \& Sons, 2003.

Daft, Richard L., Leadership Theory and Practice, Orlando USA: The Dryden Press, 1999.

Danim, Sudarwan, Visi Baru Mnajemen Sekolah; Dari unit Birokrasi ke Lembaga Akademik, Jakarta: PT Bumi Aksara, 2007.

Gibson, James L. et.al, Organization Behavior, structure and process, Foutrteenth Edition, New York: Mc-Graw Hill, 2012.

Griffin, Ricky W. dan Gregory Moorhead, Organizational Behavior: Managing People and Organizations, SouthWestern: Cengage Learning, 2014. 
Hellriegel, Don and John W. Slocum, Jr, Organizational Behavior tenth edition, Canada: Thomson, 2004.

Hoy, Wayne K. dan Cecil G. Miskel, Educational Administration:Theory, Research, and Practice, Sixth Edition, Singapore Mc-Graw Hill, 2001.

Jax, Steve M., Organizational Psychology, A Scientist-Practitioner Approach, John Wiley \& Sons, Inc, Canada, 2002

Kreitner, Robert dan Angelo Kinicki, Organizational Behavior. USA: Richard D. Irwin, Inc, 1992.

Leithwood, Kenneth dan Rosanne Stainbach, Expert Problem Solving, Evidence from School and District Leaders, State University of New York, 1995.

Lim, Ghee Soon and Richard L. Daft, The Leadership Experience in Asia, Singapore: Thomson, 2004.

Luthans, Fred, Organizational Behavior An Evidence-Based Approach, New York: McGraw-Hill, 2010.
McArthur, Caroliee, Teacher Retention In Special Education: Eficacy, Job Satisfaction and Retention of Teacher in Private Schools Serving Students with Emotional Behavioral Disabilities, 2008.

McKee, Annie, Management: A Focus On Leaders, New Jersey: Prentice Hall, 2012.

Owen, Hilarie, Vicky Hodgson, and Gazzard, Nigel Gazzard, The Leadership Manual; Your Complete Practical Guide to Effective Leadership, Pearson Education, Great Britain. 2004.

Robbins, Stephen P. and Timothy A. Judge. Organizational Behavior. New Jersey: Person Education, Inc. 2007.

Schermerhorn, Hunt, dan Osborn, Organizational Behavior. USA: Jhon Wiley \& Sons, Inc. 2005.

Yukl, Leadership in Organization, New Jersey: Pearson-Prentice-Hall, 2006. 